\title{
Barriers and strategies to integrate medical genetics and primary care in underserved populations: a scoping review
}

\author{
Ann F. Chou ${ }^{1}$ (1) $\cdot$ Ashten R. Duncan ${ }^{2} \cdot$ Gene Hallford $^{3} \cdot$ David M. Kelley $^{1} \cdot$ Lori Williamson Dean $^{4}$ \\ Received: 22 September 2020 / Accepted: 18 January 2021 / Published online: 1 February 2021 \\ (C) The Author(s), under exclusive licence to Springer-Verlag GmbH, DE part of Springer Nature 2021
}

\begin{abstract}
Despite clinical and technological advances, serious gaps remain in delivering genetic services due to disparities in workforce distribution and lack of coverage for genetic testing and counseling. Genetic services delivery, particularly in medically underserved populations, may rely heavily on primary care providers (PCPs). This study aims to identify barriers to integrating genetic services and primary care, and strategies to support integration, by conducting a scoping review. Literature synthesis found barriers most frequently cited by PCPs including insufficient knowledge about genetics and risk assessment, lack of access to geneticists, and insufficient time to address these challenges. Telegenetics, patient-centered care, and learning communities are strategies to overcome these barriers. Telegenetics supplements face-to-face clinics by providing remote access to genetic services. It may also be used for physician consultations and education. Patient-centered care allows providers, families, and patients to coordinate services and resources. Access to expert information provides a critical resource for PCPs. Learning communities may represent a mechanism that facilitates information exchange and knowledge sharing among different providers. As PCPs often play a crucial role caring for patients with genetic disorders in underserved areas, barriers to primary caremedical genetics integration must be addressed to improve access. Strategies, such as telegenetics, promotion of evidence-based guidelines, point-of-care risk assessment tools, tailored education in genetics-related topics, and other system-level strategies, will facilitate better genetics and primary care integration, which in turn, may improve genetic service delivery to patients residing in underserved communities.
\end{abstract}

Keywords Genetics · Primary care · Scoping review $\cdot$ Telemedicine $\cdot$ ECHO $\cdot$ Underserved populations $\cdot$ Rural health $\cdot$ Care coordination

\section{Introduction}

Primary care has a critical role in medical genetics, as the field has reached a defining point. While significant progress has been made

Ann F. Chou

ann-chou@ouhsc.edu

1 Department of Family and Preventive Medicine, College of Medicine, The University of Oklahoma Health Sciences Center (OUHSC), 900 NE 10th St., Oklahoma City, OK 73151, USA

2 School of Community Medicine, OUHSC, Tulsa, OK, USA

3 Department of Pediatrics, College of Medicine, OUHSC, Oklahoma City, OK, USA

4 Department of Genetic Counseling, College of Health Professions, The University of Arkansas for Medical Sciences, Little Rock, AR, USA in expanding and improving access to and knowledge of genetic services through rapid advances in both clinical practice and technological innovation, serious gaps remain in the delivery of genetic services to medically underserved populations. These gaps are created by disparities in the distribution of medical genetic workforce and limited health insurance reimbursement for genetic testing and counseling (Chou et al. 2009; Senier et al. 2015; Cooksey et al. 2005; Cooksey et al. 2006; Maiese et al. 2019). To bridge these gaps, integrating genetic services into primary care has been singled out as a priority. Primary care often serves as the only access point to medical care for many patients, especially in rural areas where there are shortages of medical professionals.

In the US, the shortage of genetic services workforce has been well documented (Cooksey et al. 2005; Cooksey et al. 2006). At the present, more than 600 genetic counseling positions remain unfilled (Henson et al. 2016; Stein 2016). Medical genetics residency positions face similar vacancies, and an increasing number of clinicians trained in genetics are 
leaving medical service positions to fill a growing number of job openings in biotechnology (Cichon and Feldman 2014). A national survey found that $68 \%$ of participating organizations had many vacancies in the area of geneticists and genetic counselors (Maiese et al. 2019).

Moreover, advances in next-generation sequencing have improved how we identify genetic etiologies while simultaneously increasing the demand for professionals qualified at interpreting these findings. As the technology matures, direct marketing of gene panels to consumers and physicians has resulted in more testing (Cornel and van El 2017). The cumulative effects of these trends are lengthy wait times for appointments, increased potential for misinterpretation of genetic test results, and overworked providers (Kaye et al. 2019). An American College of Medical Genetics (ACMG) survey showed that these trends have severely impacted families needing services: $46 \%$ of families of children with special healthcare needs experienced difficulty accessing services, and $42 \%$ of families had to wait over a month on average to see a genetic service provider (Kaye et al. 2019; Maiese et al. 2019).

Engaging, leveraging, and preparing the non-genetics healthcare workforce to deliver genetics-related services are needed to reduce disparities and meet the increasing demands for services. Primary care providers (PCPs), especially those practicing in rural areas, serve as points of entry and provide a pathway for patients and families to access appropriate care. In the absence of genetic specialists, PCPs often play a crucial role in caring for children and adults with genetic disorders (Andermann and Blancquaert 2010). Integrating genetic services delivery into primary care may potentially improve access to necessary services. In other words, optimal delivery of genetic services in many cases may rely heavily on the efforts of PCPs. To that end, strategies to support and better equip PCPs in delivering genetics-related care need to be identified, assessed, and implemented. The objectives of this scoping review are to (1) assess potential barriers to the integration of medical genetics and primary care, and (2) develop strategies to support the integration and mitigate barriers identified.

\section{Methods}

Some evidence has emerged in recent years to explore the topic surrounding integration of medical genetics into primary care. We conducted a scoping review to lend some clarity to this complex question as well as to refine and inform subsequent inquiries (Mays et al. 2001; Pham et al. 2014). The approach for this scoping review is based on Arksey and O'Malley's framework: (1) identifying a research question; (2) searching relevant literature; (3) selecting articles; (4) charting the data; and (5) summarizing and reporting results (Arksey 2005).

\section{Identifying a research question}

This study was guided by the question, "What are barriers to the integration of genetic services and primary care?" For the purpose of this study, the scoping review is defined as a research synthesis that aims to map the literature on a particular topic or research area as well as identify key concepts; gaps in the research; and types and sources of evidence to inform practice, policymaking, and research (Daudt et al. 2013).

\section{Literature search}

To capture all relevant literature, the search strategies focused on broad topics, including interface of genetics and primary care, role of medical geneticists, and patient-centered care. We used a systematic approach centered on the aforementioned topics to search Ovid MEDLINE without any restrictions on the article publication dates up to February 2020.

For the initial searches, we used the following search terms: healthcare delivery, primary care, child health services, medical homes, underserved populations, vulnerable populations, genetics, genetic counseling, access to genetic services, infrastructure, financial, legal, and barriers. Based on initial search results and review, we included additional search terms to identify potential strategies, such as genetic risk assessment, patient-centered care, telegenetics, telemedicine, learning communities, disease management model, and patient satisfaction. We combined productive search terms with other productive search terms to conduct a Boolean search in order to yield results that were more specific to the overall review topic. These initial search results were limited to those in English language, involved human subjects only, and did not contain primary DNA sequencing data and/or analyses. Upon article retrieval, we reviewed the bibliographies of the articles in an attempt to identify additional titles. Since literature related specifically to PCPs, genetic services, and underserved populations is notably sparse, we further included and analyzed references from gray literature, using Google and Yahoo search engines. Snowballing method was applied whenever appropriate.

\section{Citation management}

References from the MEDLINE search and gray literature were extracted and exported into a bibliographic software, EndNote [v.X9, Clarivate, Philadelphia, PA], for management and analysis. Duplicate citations were removed, and all remaining titles and abstracts were screened for relevance

\section{Article selection and exclusion criteria}

We excluded references based on the following criteria: (1) published more than 15 years ago, (2) little relevant 
information or duplicate content that was more fully described in other titles, (3) peripherally related to the intersection of primary care and genetic services, and (4) focus on different aspects of genetics-oriented research with no primary care tie-in. We preemptively addressed any issues of double counting by reviewing all included systematic reviews and their bibliographies. We did not include references already included in the previously published systematic reviews. Figure 1 presents a flow chart of reference inclusion and exclusion.

\section{Data characterization and synthesis}

Upon screening the titles and abstracts, relevant citations were included for full-text review. Two reviewers read all of the articles and then assigned each to one of three categories for analysis: (1) barriers to integrating primary care and genetic services, (2) current landscape of genetic service delivery, or (3) primary care support and integration strategies. We constructed evidence tables to organize and summarize the articles. Articles in

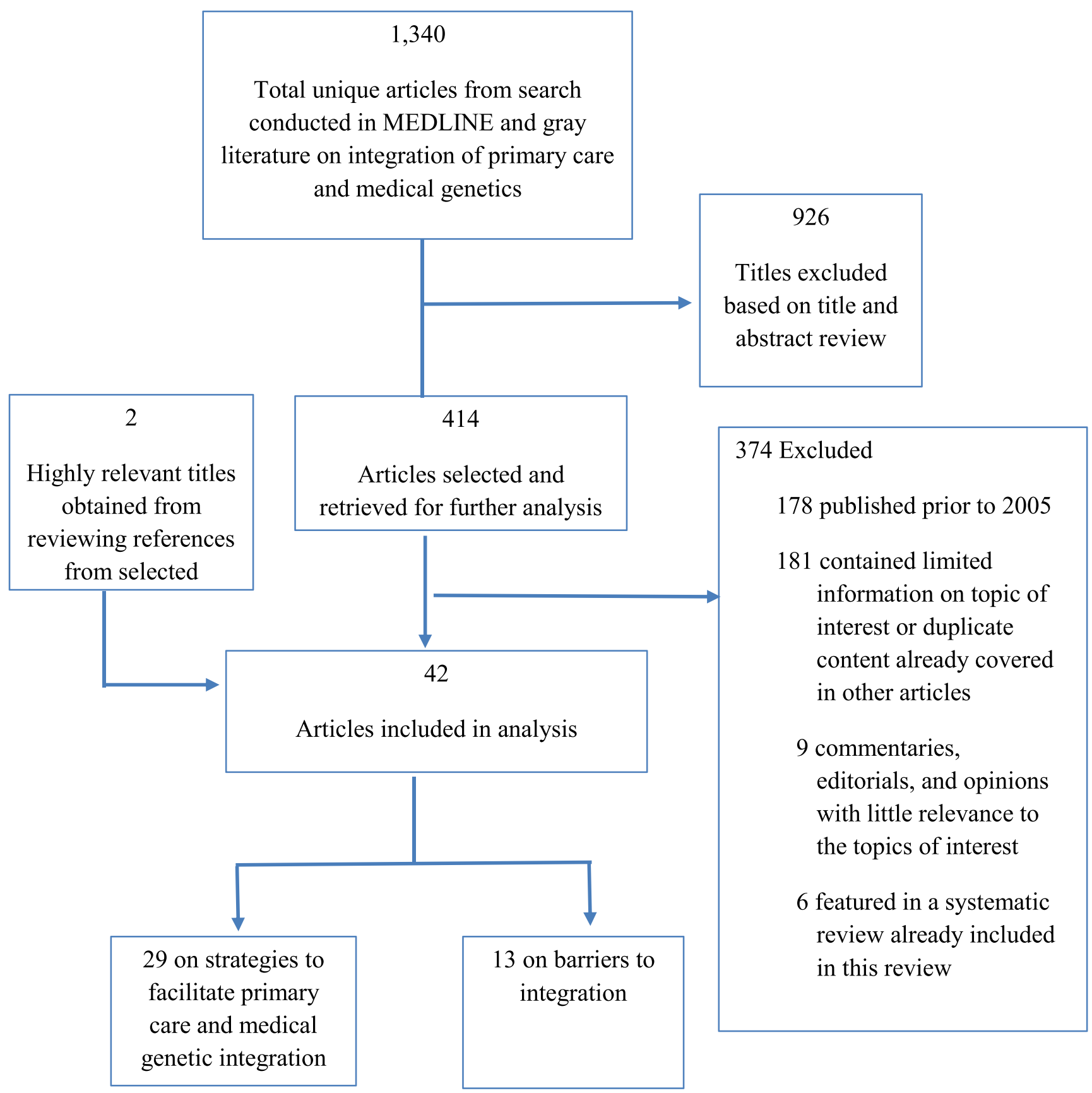

Fig. 1 Summary of literature searches and article selection 
category one were summarized in Table 1 and those in categories two and three are collated in Table 2.

\section{Results}

The literature search yielded 1340 unique titles. These titles were scanned for relevance based on titles and abstracts, where 414 titles were selected for further analysis (Fig. 1). The final set retained 42 articles, with 13 titles describing barriers encountered in the integration of genetic services and primary care (Table 1 ) and 29 related to primary care support and genetics integration strategies (Table 2).

Of the 42 articles analyzed, we identified 12 cross-sectional studies, seven reviews (systematic and basic literature), five randomized controlled trials, three implementation studies, and two pre-post analyses. We also found relevant information in one quantitative retrospective study, five qualitative studies, one mixed-methods study, two commentaries, a meeting report, a case report, a program evaluation, and an article detailing model development and evaluation.

\section{Barriers for PCPs}

Barriers to providing genetic services that were cited by PCPs include insufficient time to provide these services, a lack of access to genetic referrals and resources, and those related to limited knowledge in genetics (e.g., lack of clinical guidelines/care pathways, training, and confidence in genetics) (Carroll et al. 2009; McCahon et al. 2009; Najafzadeh et al. 2013; Wakefield et al. 2018). In the sole systematic review identifying barriers in our search, Mikat-Stevens and colleagues found that barriers most frequently mentioned by PCPs include a lack of knowledge about genetics and genetic risk assessment, concern for patient anxiety, a lack of access to geneticists, and insufficient time to address these challenges (Mikat-Stevens et al. 2015). In addition to reporting limited knowledge and difficulties accessing resources, expertise, and training, PCPs in rural areas expressed concerns about cost, distance, and poor patient engagement (Harding et al. 2019).

These barriers impact practice, further impeding care delivery to patients in need of genetic services. Some studies showed that most clinicians in primary care do not provide genomics-based care largely due to lack of knowledge (Lopes-Junior et al. 2017), or unavailability of clinical guidelines (Najafzadeh et al. 2013). Most PCPs would neither order genetic testing nor refer their patients to a genetics specialist as the first step in their evaluation (McCahon et al. 2009; Tarini et al. 2015). Kne and colleagues showed that there is even a lack of knowledge about how to utilize genetic counselors' services appropriately (Kne et al. 2017). Even in cases where PCPs have received some genetic education, the knowledge and confidence gaps remain. In a sample of recently trained PCPs who had formal genetics education and positive views of the utility of genetic testing, the respondents felt unprepared to work with patients at risk for genetic conditions and were not confident about interpreting test results. Moreover, they were concerned about insurance discrimination and lacked trust in companies that offer genetic tests (Hauser et al. 2018).

\section{Primary care and medical genetics integration}

Mitigating barriers to integrating genetics into primary care, we identified a set of strategies for implementation. These strategies center on innovative service delivery approaches that go beyond face-to-face encounters with patients as well as educational outreach and support for PCPs.

As the use of telemedicine has become more integrated into care delivery to remote areas, its application in genetics has become more widely accepted. Moreover, results from a number of studies included in this review state that patients are generally just as satisfied, if not more, with telegenetics services as they are with traditional face-to-face consultations (Buchanan et al. 2015; Hilgart et al. 2012; Otten et al. 2016a; b). In addition, digital platforms and other electronic resources, such as web meetings, can be leveraged to deliver education or "refreshers" to PCPs as well as access to specialists, thereby empowering them to provide better care in their own communities (Hilgart et al. 2012). Nevertheless, barriers to access exist despite this level of satisfaction not just in the US but also beyond: one research team found that telegenetics technology uptake was significantly low throughout several European countries, which the team discovered was due primarily to a lack of financial resources, professional support, and/or knowledge, similar to their US counterpart (Otten et al. 2016a; b).

One of the ways to ameliorate the knowledge gap in genetics among PCPs is provide education and tools across a range of topics via various delivery modes and media. In a survey of PCPs, participants identified contact information for local genetic clinics, summaries of genetic disorders, referrals and testing criteria as useful information for their practice. While most preferred in-person learning, over half wanted contact with genetic counselors to answer questions and web-based education (Carroll et al. 2019). Evaluation of an interactive web-based curriculum focusing on communication; basics of genetic testing; risk assessment; ethical, legal, and social implication (ELSI) discussions; and practice behaviors demonstrated better shared decision-making and increases in ELSI discussions with patients (Wilkes et al. 2017). In addition, many innovations, such as standardized history forms and questionnaires, have been developed and disseminated to make gathering information on family history and hereditary risk factors easier for PCPs.

Patient-centered medical homes (PCMHs), which are characterized by team-based care coordinated by primary 
Table 1 Evidence on barriers to integration

\begin{tabular}{llcc}
\hline Authors, year, country & Objective & Study design & Methods/population studied \\
\hline Bell et al. (2015) & To compare effectiveness of an & Randomized & N=121 California and \\
USA & $\begin{array}{l}\text { interactive web-based genetics } \\
\text { curriculum to a text curriculum } \\
\text { for primary care providers }\end{array}$ & $\begin{array}{c}\text { controlled } \\
\text { trial (RCT) }\end{array}$ & $\begin{array}{c}\text { Pennsylvania community } \\
\text { physicians }\end{array}$ \\
& (PCPs) & A web-based genetics curriculum \\
& & with standardized patients \\
& & & administered
\end{tabular}

Carroll et al. (2019) Canada

Harding et al. (2019) Canada

Hauser et al. (2018) USA

Kne et al. (2017) USA
To determine family physicians' involvement in genomic medicine, attitudes towards clinical value, suggestions for integration of genomic medicine into practice, and necessary resources and education
Cross-sectional $N=361$ family physicians An anonymous questionnaire mailed to a random sample of 2000 family physicians in Ontario, Canada
Findings and conclusions

Around $55 \%$ of participants offered a genetic counseling referral, and about $44 \%$ recommended testing. The intervention group was more likely than the control to look into genetic counseling benefits and encourage it before testing.

Family physicians lacked confidence in their genomic medicine-related skills but identified making referrals as their main contribution. Respondents stated that they were somewhat optimistic about the contribution genomic medicine may make to patient care. Educational resources and improved communication with genetic specialists were needed in primary care settings.

PCPs endorsed the importance of genetics in primary care but identified difficulty in providing timely genetic care. Despite efforts to expand genetics continuing education opportunities, PCPs must have the ability to assess genetic risk, provide a consistent level of genetic care and testing, and refer patients appropriately.

Focus group conducted with PCPs

Cross-sectional $N=488$ PCPs in community and academic practices in New York City 2014 to $2016 ; N=15$ participated in open-ended interviews

Survey about views on genetic testing for chronic diseases sustainable adoption and dissemination of genomic medicine
To determine the rate of genetic counseling utilization by women at risk for hereditary breast and ovarian cancer (HBOC), barriers and support influencing services uptake, and possible strategies for increasing utilization
Cross-sectional $N=603$ screening mammography patients identified as being at increased risk for HBOC; at-risk women and their PCPs were mailed a referral letter for genetic counseling

$N=24$ participants in 3 focus groups
Most PCPs believed in clinical benefits of genetic testing for common chronic diseases. However, they expressed concerns about lacking the knowledge and skill to use genetics in their practices. Efforts to expand genetic testing should help identify common, actionable variants that increase chronic disease risk and should enhance PCP's training and the use of electronic health records.

Barriers to utilizing genetic counseling services included perceiving counseling as not being highly relevant nor useful for the participants, a lack of knowledge about the genetic counseling process, concerns about complexity and emotional impact, and concerns about cost. The provision of educational resources for patients during the referral process and more emphasis on counseling's importance from the PCP may help to address the 
Table 1 (continued)

\begin{tabular}{ll}
\hline Authors, year, country & Objective \\
\hline & \\
& \\
Lopes-Junior & $\begin{array}{l}\text { To determine the level of } \\
\text { et al. (2017) }\end{array}$ \\
Brazil & knowlic-related education, \\
& among nurses and physicians \\
& who provide primary care \\
& in São Paulo
\end{tabular}

Study design Methods/population studied

Cross-sectional $N=24$ physicians and 30 nurses Questionnaires administered

McCahon et al. (2009) To examine general practitioners' UK

\section{Mikat-Stevens \\ et al. (2015) \\ USA}

Najafzadeh
et al. (2013)
USA and Canada

Otten et al. (2016a) Europe attitudes towards the provision of genetic health services including familial risk assessment for common disorders in primary care settings

To review the literature to barriers against the provision of genetics services in general determine PCPs' perceived
Cross-sectional $N=797$ general practitioners, recruited from a stratified, random sample of general practitioners in England extracted from the Midlands Practices Research Consortium database

Survey collected

\section{Systematic review}

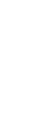
To examine physician perceptions Mixed $\quad N=28$ physicians currently about personalized medicine methods and the factors that influence decision-making in using genet- ic testing

Findings and conclusions

under-utilization of cancer genetic counseling services.

Roughly $85 \%$ of respondents stated that they received some genetic content during their undergraduate education. About $78 \%$ indicated that they did not feel prepared to deliver genomics-based health care in primary care. It was concluded that primary care nurses and physicians lack the knowledge to provide genomic-based health care.

One-third of the respondents supported being involved in family history screening and familial risk assessment for commonly seen disorders. About one third did not feel sufficiently prepared. A substantial proportion were not willing to offer these services in primary care even with training. Main barriers that were noted to providing genetics services included a lack of training and proper guidelines.

PCPs cited misperceptions, knowledge deficits, systems-level barriers to integrating genetics into practice (e.g., time constraints and lack of access), patient anxiety and fear of health insurance or social discrimination, the potential for loss of privacy for family members, and a lack of guidelines for the provision of genetic services as barriers.

The main concerns raised in the focus groups were access to clinical guidelines and training for the use of genetic testing and data interpretation. Despite the hurdles associated with personalized medicine, the physicians expressed strong interest in using genetic testing resources, pending that there would be sufficient access to the necessary knowledge and tools.

Only $28 \%$ had access to telegenetics modalities. About $17 \%$ used telephone-based genetic counseling and around 9\% used videoconferencing for patient counseling purposes. Cited barriers to access included lack of funds, professional support 
Table 1 (continued)

Authors, year, country $\quad$ Objective $\quad$ Study design $\quad$ Methods/population studied $\quad$ Findings and conclusions

\begin{tabular}{|c|c|c|c|c|}
\hline & & & & $\begin{array}{l}\text { and/or knowledge, and need. } \\
\text { Results indicated that } \\
\text { telegenetics modalities were not } \\
\text { widespread throughout Europe. }\end{array}$ \\
\hline $\begin{array}{l}\text { Paneque et al. (2016) } \\
\text { Portugal, UK, and the } \\
\text { Netherlands }\end{array}$ & $\begin{array}{l}\text { To evaluate genetics educational } \\
\text { interventions in the context of } \\
\text { primary care to determine if } \\
\text { there is a common theme to } \\
\text { direct guidelines }\end{array}$ & $\begin{array}{l}\text { Systematic } \\
\text { review }\end{array}$ & $\begin{array}{l}\text { Following the guidelines from the } \\
\text { Centre for Reviews and } \\
\text { Dissemination, five relevant } \\
\text { electronic databases searched } \\
\text { Results coded and categorized }\end{array}$ & $\begin{array}{l}\text { Current literature is insufficient } \\
\text { about how to inform educational } \\
\text { interventions in genetics for } \\
\text { PCPs. Educational initiatives } \\
\text { should be assessed using } \\
\text { changes in practice to determine } \\
\text { if they would be effective in } \\
\text { causing significant changes in } \\
\text { practice in genetic risk } \\
\text { assessment and appropriate } \\
\text { management of patients. }\end{array}$ \\
\hline $\begin{array}{l}\text { Tarini et al. (2015) } \\
\text { USA }\end{array}$ & $\begin{array}{l}\text { To examine decisions of } \\
\text { pediatricians and family } \\
\text { physicians about a diagnostic } \\
\text { evaluation for a child with } \\
\text { suspected global developmental } \\
\text { delay }\end{array}$ & Cross-sectional & $\begin{array}{l}N=484 \text { pediatricians and family } \\
\text { physicians } \\
\text { Online survey containing a clinical } \\
\text { vignette about global } \\
\text { developmental delay completed }\end{array}$ & $\begin{array}{l}\text { Almost } 75 \% \text { of the respondents } \\
\text { reported that their first step } \\
\text { would be to refer the child } \\
\text { without testing, } 22 \% \text { would test } \\
\text { only, and } 4 \% \text { would both test } \\
\text { and refer. Most physicians } \\
\text { would refer to a developmental } \\
\text { pediatrician first, and only } 5 \% \\
\text { would refer to a geneticist. The } \\
\text { most commonly ordered test } \\
\text { was general biochemical testing. } \\
\text { Few PCPs would order genetic } \\
\text { testing or refer to a genetics } \\
\text { specialist as a first evaluation } \\
\text { step. }\end{array}$ \\
\hline $\begin{array}{l}\text { Wakefield et al. (2018) } \\
\text { Australia }\end{array}$ & $\begin{array}{l}\text { To examine: (1) frequency and } \\
\text { depth of family cancer histories } \\
\text { taken by providers, (2) barriers } \\
\text { to regular family history-taking, } \\
\text { and (3) provider confidence in } \\
\text { discussing genetics related } \\
\text { topics with childhood cancer } \\
\text { survivors }\end{array}$ & Qualitative & $\begin{array}{l}N=54 \text { providers ( } 8 \text { tertiary center } \\
\text { providers and } 46 \text { PCPs) across } \\
\text { New Zealand and Australia } \\
\text { Semi-structured interviews } \\
\text { completed }\end{array}$ & $\begin{array}{l}\text { While family history-taking is not } \\
\text { sufficient to identify all } \\
\text { survivors suitable for genetic } \\
\text { assessment, recommendations } \\
\text { for regular history-taking are not } \\
\text { being implemented in tertiary or } \\
\text { primary care. Additional } \\
\text { primary care-targeted genetic } \\
\text { education is necessary given } \\
\text { their ability to review family } \\
\text { histories of pediatric cancer } \\
\text { survivors. }\end{array}$ \\
\hline
\end{tabular}

care to manage complex or chronic diseases, had originated as a care delivery model in pediatrics. PCMHs have been cited as being advantageous in many ways, including providing better access to, quality and continuity of, and patient satisfaction with medical care (Agency for Healthcare Research and Quality 2019; David et al. 2015). PCMHs have also been shown to be practical for underserved populations (Balachandra et al. 2009; Mead et al. 2014). Adapted specifically to enhance access to and quality of genetic services, Kubendran and colleagues developed and tested a collaborative services delivery model derived from the PCMH concept that consisted of a pediatrician, medical geneticist, and genetic counselor (Kubendran et al. 2016). This model also relies on the availability of telegenetics and involvement of families. To reduce long wait for referrals to geneticists, the proposed model refers patients who have genetic indications of a syndromic etiology directly to a geneticist via telegenetics, with all others delegated to primary care via an in-person pediatric or genetic counseling clinic before following up with the geneticist. This type of clinic provides a model of collaborative care that exemplifies a medical home neighbor and the integration of genetics into primary care (Kubendran et al. 2016). As partners in a PCMH, providing tools, education, and resources empower families to assume a 
Table 2 Strategies to facilitate delivery of genetic services via integration with primary care

\begin{tabular}{llcc}
\hline Authors, year, Country & Objective & Study design & Methods/population studied \\
\hline Bernard et al. (2010) & $\begin{array}{c}\text { To determine whether having a } \\
\text { genetic counselor on site at a } \\
\text { USA }\end{array}$ & $\begin{array}{c}\text { Pretest/ posttest } \\
\text { analysis }\end{array}$ & $\begin{array}{c}N=84 \text { patients with a concerning } \\
\text { family history that the genetic }\end{array}$ \\
& $\begin{array}{l}\text { improved the quality of the } \\
\text { counselor discussed with the } \\
\text { provider }\end{array}$ & &
\end{tabular}

Findings and conclusions medical records

Buchanan et al. (2015) To report on the cost, patient USA

Carroll et al. (2009) Canada

Cartmell et al. (2018) USA

\footnotetext{
Christianson

et al. (2012) USA
} use of genetic services, satisfaction, and attendance comparing telegenetics with in-person cancer counseling services among patients

To increase PCPs' awareness and

\section{Randomized trial $N=162$ patients from 4 rural oncology clinics randomly assigned to either in-person or telegenetic counseling}

Results supported the conclusion that behavioral modification is difficult in a primary care clinic. It is highly recommended that efforts and funding be directed towards education and development of tools to assist with collecting and interpreting family history information.

The cost of cancer genetic counseling via telegenetics was less than half of the cost of in-person counseling services. Patient satisfaction was high among those who used telegenetics services, even for those with a low level of comfort with computers. The results supported the telemedicine delivery models. knowledge of clinical genetics, and confidence in their ability to provide genetic services

Cross-sectional

$N=29$ participants (response rate $=$ $72 \%)$

An initial questionnaire completed, followed by a workshop, and then a follow-up questionnaire.

Implement-ation
study cross-sectional survey to document the availability of five key Commission on Cancer accreditation standards for cancer centers
16 of 17 eligible cancer centers in South Carolina completed a survey

Survey included questions about the availability of (1) patient navigation; (2) distress screening; (3) genetic risk assessment and counseling; (4) survivorship care planning; and (5) palliative care

\footnotetext{
To assess input offered by PCPs Qualitative about the incorporation of a family health history risk assessment tool into a community health care system
}
$N=14$ PCPs and 2 mid-level pro- viders

3 Semi-structured focus groups conducted
There was a need for genetic education for PCPs. The relevant, case-based genetic information provided in an interactive, interdisciplinary learning environment was able to improve the knowledge and confidence of PCPs.

Forty-four-percent provided patient navigation; $31 \%$ conducted distress screening; and $44 \%$ reported providing genetic risk assessment and counseling. Over $85 \%$ of the centers reported having an active palliative care program, palliative care providers and a hospice program, but fewer had palliative outpatient services (27\%), palliative inpatient beds $(50 \%)$ or inpatient consultation teams $(31 \%)$. The survey is a potentially practical method for monitoring statewide availability of cancer patient support services.

The development of family history collection tools and educational resources to improve PCP genetic literacy alone may not be sufficient to facilitate the integration of genomic medicine into primary care. The results showed that PCPs who wish to integrate genomic medicine services into their practices will need a supportive infrastructure including access 
Table 2 (continued)

Authors, year, Country Objective

Study design Methods/population studied

Findings and conclusions

Cragun and Pal (2013) To review the literature for USA

David et al. (2015)

USA

de Hoog et al. (2014)

The Netherlands cancer predisposition health care system recommendations to feasibly and appropriately identify patients at high risk of inherited

To review information about patient-centered medical homes (PCMH) to implement genomic medicine in a patient-centered

Review Literature searched and analyzed

Literature review Literature and insights from workshops convened by the Institute of Medicine Roundtable on Translating Genomic-Based Research for Health analyzed

Systematic searches of PubMed, Embase, and Cinahl for articles published 2002-2012 performed; relevant articles extracted and analyzed

\section{characteristics of existing review} family his-tory tools and explore potential use in primary care settings
Hamilton et al. (2014) To identify characteristics of USA

Harding et al. (2019) Canada health care organizations
Systematic

Qualitative genetic services that affect the adoption of these services by
To explore the self-identified needs of both urban and rural PCPs to provide genetic care
Qualitative

$N=10$ key informant; one urban and two rural focus groups of PCPs in Ontario, Canada

Using a qualitative grounded theory approach, interview and focus group data synthesized and analyzed to geneticists or genetic counselors and evidence-based guidelines.

Medical understandings of diseases due to genetic variation will continually evolve in the future. Advancements to benefit patient care will necessitate enhanced PCP proficiency in genetics and a collaborative, multidisciplinary approach.

Due to the complexity and heterogeneity of primary health care, genomic medicine integration must optimize the use and cost of personalized health care and continue to support the primary care workforce.

Eighteen family history tools were identified: six genetic, two for cardiovascular disease, and ten for cancer. The six generic tools were partly tested in primary care, were mainly computerized, rarely included management recommendations for the physician, and were partly validated against a reference standard (i.e., genetic counselor). No family history tool allows electronic transfer of family history information to electronic medical record systems. Family history tools improved identification of patients at high risk for disease. Implementation cannot be advised yet with limited validation studies.

Adoption and implementation of genetic services will require multilevel measures that include education, opportunities to underscore the benefits of genetic medicine, strategies for making genomic medicine less complex and for accessing genetics expertise, and resources for assessing the value of genetic information.

PCPs identified a need to integrate genetics into primary care practice but they perceived barriers, which included a lack of knowledge and confidence, access to timely consultations, and clearly defined roles for 
Table 2 (continued)

Harvey et al. (2007)

USA

Hilgart et al. (2012) UK

Kaplan (2014) USA

Kaye (2012)

USA

Kubendran et al. (2016)

USA
To investigate what individuals with genetic conditions and their families experience during encounters with their health care providers

To identify studies of genetic services carried out through video-conferencing to determine the value of telegenetics

\author{
Cross-sectional
}

$N=5915$ participants recruited from organizations that are members of the Genetic Alliance.

Surveys completed
Systematic review
Relevant literature published between 1996 and 2011

Search of MEDLINE, EMBASE, Psych-INFO, CINAHL, British Nursing Index, Cochrane Library, and Web of Science.
To explore if the frequency of discussions with physicians about breast cancer risk, risk reduction options, and appropriate referrals is significantly affected by the provision of an individualized risk report

To explore the structure of genetic Literature review medicine and its interface with primary care, with a particular focus on the delivery of care

\section{$N=1235$ multi-ethnic and multi-lingual women aged 40-74 from 2 primary care practices, randomly assigned to intervention $(n=580)$ or control $(n=655)$ \\ Intervention group received individualized risk report from BreastCARE \\ Literature relevant to different models of genetic services delivery, quality improvement tools, benefits of information networks examined and discussed}

$N=265$ patients

To develop a collaborative service delivery model with the aim to facilitate access to genetic services themselves and specialists. Interventions that are directed at accessible, just-in-time support and consultation have the potential to empower PCPs to manage their patients' genetic conditions.

About $64 \%$ reported receiving no genetics education materials from their providers. Results stress the importance of allied health providers and demonstrate the need for a team-based approach to care. Education of health care professionals about genetics is critical.

Most patients received telegenetics consultation using video-conferencing with a genetics specialist. All studies reviewed indicated high patient satisfaction with telegenetics. Many studies had small sample sizes and lack of statistical analyses. Telegenetics may be useful for providing routine counseling and evaluation of pediatric patients.

BreastCARE showed that combining an easy-to-use risk assessment tool with individualized risk reports at the point of care can successfully promote discussion of breast cancer risk reduction between patients and PCPs.

Several models for genetics service delivery, along with related quality improvement tools, were discussed for implementation.

Delivery of genetic services to all population will likely be handled by PCPs with the support of genetic health care professionals.

Of the 265 patients, $44 \%$ were evaluated by a pediatrician and genetic counselor in person first, and $71 \%$ of those then saw a geneticist. Patients were able to secure a pediatrician and genetic counselor visit within 6 weeks while new appointment with a geneticist ranged from 3 to 9 months. Satisfaction with this protocol 
Table 2 (continued)

Authors, year, Country Objective

To determine the acceptability of telegenetics and other cancer genetic counseling models of service delivery in geographically remote settings et al. (2014) USA

Orlando et al. (2014) USA

Otten et al. (2016a) The Netherlands

\footnotetext{
Rahimzadeh and Bartlett (2014)
}

To describe the impact of the Genomic Medicine Model (GMM)for primary care on the identification of patients at increased risk and the resources needed to manage risk
To examine the potential benefits of online counseling services for patient access to care and satisfaction
To provide re-commendations for Commentary future translational initiatives that aim to maximize the
Study design Methods/population studied

visit and then a geneticist visit if indicated

Appointment and referrals tracked and patient satisfaction surveys administered
Cross-sectional

Implement-ation $\quad N=1184$ adult patients effectiveness Patients going in for routine check-ups from October 2009 to April 2012 input information into MeTree, a web-based program that collects family and personal medical history and other information from patients for risk calculation

$N=149$ participants, including new referrals with history-based risk susceptibility

\section{Pre-post survey $\quad N=57$ patients participating in online counseling}

Findings and conclusions

was high. The

pediatrician/genetic counselor clinic resembles the type of collaborative care provided by a medical home. Genetic and primary care integration and genetic services provided via telegenetics offer a novel solution to improve access to genetic care, especially for residents of chronically underserved regions.

Participants were open to using telegenetics services as a means of receiving expert, one-on-one cancer genetic counseling locally. The acceptability of care models varied significantly based on geographic barriers, perceived cancer risk, or perceived risk for a hereditary cancer susceptibility disorder.

With marked success, MeTree can integrate guideline risk stratification and management into the care of primary care populations. It is anticipated that using this system will lead to an increase in resource (e.g., genetic counseling). In accordance with the GMM, MeTree is one way to anticipate increased demands and inform guidelines.

Results suggest online counseling is valuable in addition to existing in-person care. Participants who chose online counseling reported higher satisfaction. The psychological outcomes of online patients were comparable to controls. Technical limitations do exist, but this method of telegenetics service delivery is feasible for implementation. capacities of genomic medicine, without interfering with primary health care delivery
Literature primary care and genomic medicine reviewed to make recommendations
Since primary care is charged with health education, advocacy, and prevention more than most specialties, the implementation of genomic medicine tools needs to preserve the whole-person care philosophy, uphold medical ethics, and develop ways to translate genetic risk of common chronic diseases into clinically actionable methods. 
Table 2 (continued)

\begin{tabular}{|c|c|}
\hline Authors, year, Country & Objective \\
\hline $\begin{array}{l}\text { Rolnick et al. (2011) } \\
\text { USA }\end{array}$ & $\begin{array}{l}\text { To elicit genetic counselors' } \\
\text { perspectives on the } \\
\text { identification of high-risk pa- } \\
\text { tients and barriers to referral of } \\
\text { high-risk patients for cancer } \\
\text { genetic counseling services }\end{array}$ \\
\hline
\end{tabular}

$\begin{array}{lc}\text { Study design } & \text { Methods/population studied } \\ \text { Cross-sectional } & N=28 \text { genetic service providers } \\ & \text { from 8 participating sites } \\ & \text { A 17-question survey deployed } \\ & \text { from March to June 2009 }\end{array}$

Sane et al. (2015) Australia

Saul (2013)

USA

\section{Scott and Trotter \\ (2013)}

USA

Stevens and Kim
(2016)

USA

Traxler et al. (2014)

USA
To investigate the perceived interest in private genetic counseling services in collaboration with PCPs in Australasia

To provide information from the colloquium on the delivery of genetic services in pediatric primary care practices

Report - colloquium

\section{Cross-sectional $\quad N=78$ members of the Australasian Society of Genetic Counselors Online survey administered.}

Articles and other information from the colloquium sponsored by the Health Resources and Services Ad-ministration Maternal and Child Health Bureau reviewed

To evaluate current research to determine suitability of primary care with the provision of genetic services

Commentary

Literature related to the intersection of primary care and genetic health services examined and used to provide recommendations for integration from March to June 2009

Findings and conclusions

Results suggested that referrals from specialized practices outnumber those from primary care practices. Participants discussed using a family history tool that could be modified to screen all primary care patients. Participants perceived that the patients referred to them assign a low priority to familial cancer risk genetic counseling.

About $85 \%$ of participants showed interest towards the potential for clinical work in private practice, with many expressing preferences for collaboration with clinical geneticists instead of general practitioners.

Expansion into private practice is more likely to occur in primary care.

Four major recommendations were generated: (1) define practical genetics and genomics use for pediatricians; (2) identify, develop, and provide the tools and resources that are needed to integrate genetics and genomics into primary care; (3) integrate genetics and genomics into primary care training at all levels; and (4.) provide an evidence base for optimal integration of genetics and genomics.

Genetic health care services are complex, and genetic tests and results from those tests have specific risks and benefits, especially for pediatric patients. The longitudinal nature of primary care provides the opportunity to obtain and continually update the family history, which is one of the most powerful genetic tools.

Data analyzed from the families of Children's health care experiences 289,672 children who responded to surveys in 2003 , 2007, and 2011-2012.

Indicators of 4 medical home features (access, continuity, comprehensiveness, and family-centeredness) assessed

Implement-ation $\quad N=2159$ women screened 2012-13 have become more aligned with the medical home model. This is the case in spite of an increase in child vulnerability during the same time frame. Children with multiple sociodemographic risk factors seemed to experience larger changes in the studied indicators.

The project identified underserved and minority women at 
Table 2 (continued)

\begin{tabular}{|c|c|c|c|}
\hline Authors, year, Country & Objective & Study design & Methods/population studied \\
\hline & $\begin{array}{l}\text { state public health centers } \\
\text { serving mostly women who are } \\
\text { minorities and/or disadvantaged } \\
\text { and to implement a system for } \\
\text { genetic education and follow-- } \\
\text { up }\end{array}$ & & $\begin{array}{l}\text { A positive B-RST screening result } \\
\text { was obtained for } 130 \\
\text { women-110 agreed to follow } \\
\text { up. }\end{array}$ \\
\hline $\begin{array}{l}\text { Ufer et al. (2018) } \\
\text { USA }\end{array}$ & $\begin{array}{l}\text { To describe the Care } \\
\text { Coordination: Empowering } \\
\text { Families (CCEF) training } \\
\text { program and results of an } \\
\text { evaluation from its pilot } \\
\text { program across seven states }\end{array}$ & $\begin{array}{l}\text { Program } \\
\text { evaluation }\end{array}$ & $\begin{array}{l}N=190 \text { family caregivers of } \\
\text { children with genetic conditions } \\
\text { and other special healthcare } \\
\text { needs } \\
\text { Participant asked to evaluate } \\
\text { CCEF prior to and immediately } \\
\text { following the training }\end{array}$ \\
\hline
\end{tabular}

Findings and conclusions

state public health centers serving mostly women who are minorities and/or disadvantaged genetic education and followowng the training

Unim et al. (2019)

Europe, Canada, USA, Australia, New Zealand
To evaluate genetic services and Systematic identify delivery models for the provision of genetic testing in European and extra-European countries
Review

$N=117$ articles included

Five electronic resources accessed to identify articles published 2000-2015 increased risk for hereditary breast and ovarian cancer who would not have otherwise had access to appropriate care. Widespread utilization of the study protocol may contribute to a reduction in health inequity among high-risk and minority populations.

Families who attended the training reported being the primary source of care coordination for their children and $83.7 \%$ saw their role in their child's healthcare changing as a result of the training. Findings suggest that peer support and communication with providers increased as a result of the training over the course of the study.

Study identified 148 genetic programs, offering genetic tests mainly for BRCA1/2, Lynch syndrome, and newborn screening. As healthcare professions with different backgrounds were increasingly providing genetic services, the study classified the programs into five models: (1) geneticists model; (2) primary care model; (3) medical specialist model; (4) population screening programs model; and (5)

direct-to-consumer model. While appropriate model depends on the type of system in which care is delivered, these models require the integration of genetics into all medical specialties, collaboration among health professionals, and redistribution of professional roles.

$N=121$ PCPs from California and While the intervention group Pennsylvania randomized to either intervention or control group

Intervention consisted of a six-hour interactive web-based curriculum covering communication skills, basics of genetic testing, risk assessment, ethical, legal, and social implications (ELSI), and practice behaviors; controls received traditional approach demonstrated significant increases in learning and retention and shared decision-making practices, there were few differences in behavior changes around ELSI discussions. The main barrier could be that busy physicians need systems-level support to engage in meaningful discussions around genetics issues. 
Table 2 (continued)

\begin{tabular}{|c|c|c|c|c|}
\hline Authors, year, Country & Objective & Study design & Methods/population studied & Findings and conclusions \\
\hline $\begin{array}{l}\text { Williams et al. (2018) } \\
\text { USA }\end{array}$ & $\begin{array}{l}\text { To test the effectiveness of an } \\
\text { enhanced genomic report on } \\
\text { patient-centered outcome } \\
\text { domains, which included } \\
\text { communication, engagement, } \\
\text { and satisfaction }\end{array}$ & RCT & $\begin{array}{l}N=52 \text { parents of children with } \\
\text { undiagnosed congenital } \\
\text { disorders who had participated } \\
\text { in a previous study offering } \\
\text { whole-genome sequencing for } \\
\text { their affected child } \\
\text { Parents first stratified by receipt of } \\
\text { a diagnostic result and } \\
\text { uninformative result and then } \\
\text { randomized within each group } \\
\text { to an intervention arm to receive } \\
\text { the GenomeCOMPASSTM } \\
\text { report or to the usual care arm to } \\
\text { receive a summary letter from } \\
\text { the medical geneticist }\end{array}$ & $\begin{array}{l}\text { Parents for whom the report was } \\
\text { most relevant were highly } \\
\text { satisfied with the report, } \\
\text { indicating that they felt more } \\
\text { confident and better able to } \\
\text { advocate for their child and that } \\
\text { they had shared the report with } \\
\text { different people involved in } \\
\text { their children's care. } \\
\text { Unsolicited communication } \\
\text { from external providers } \\
\text { confirmed the value of the } \\
\text { enhanced report to providers. } \\
\text { This resource can support } \\
\text { patients, their families, and } \\
\text { healthcare providers using the } \\
\text { electronic health records to } \\
\text { disseminate accurate genetic } \\
\text { information, provide real-time } \\
\text { management support, and to } \\
\text { connect families with appropri- } \\
\text { ate resources. }\end{array}$ \\
\hline
\end{tabular}

primary role in care coordination, which results in higher satisfaction and improvement in healthcare outcomes (Ufer et al. 2018; Williams et al. 2018).

\section{Discussion}

Findings of this review show that, despite some progress, challenges remain in the integration of primary care and genetic services. Nevertheless, several articles have identified specific barriers that are amenable to interventions.

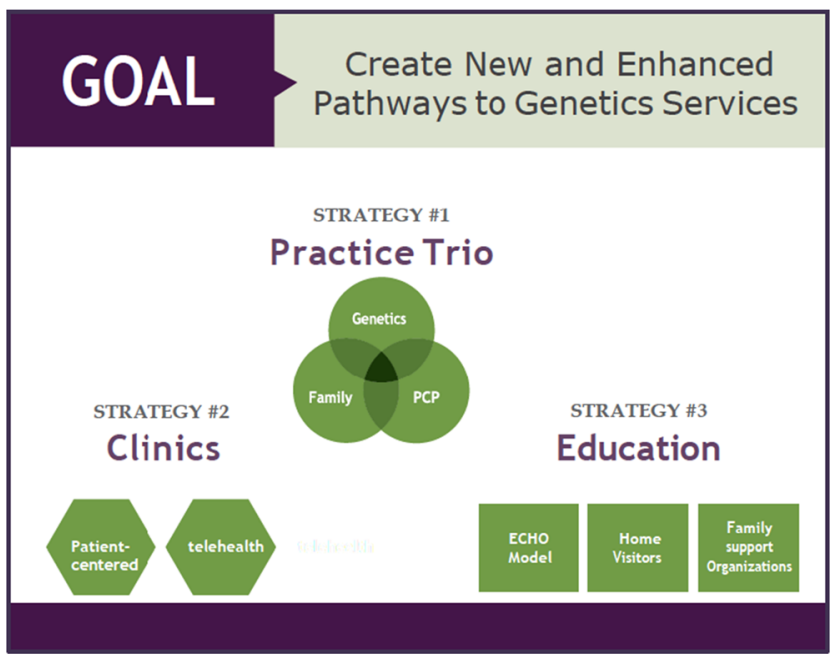

Fig. 2 Strategies creating new pathways to genetic services via integration of medical genetics and primary care

\section{Recommendations}

Since PCPs in medically underserved areas already take on the role of bridging the gap between primary care and genomic medicine, we must make it easier for these providers to access specialists and increase their genetics expertise to help their communities. Most PCPs have limited experience with clinically operationalizing the ever-growing body of actionable genetic information and are insufficiently prepared to incorporate this information into their current practices. The scoping review findings suggest the following strategies to bridge the gap in clinical knowledge and enhance access to genetic services: telegenetics, partnership trios that expands upon the PCMH concept, and learning communities (Fig. 2).

\section{Telemedicine/telegenetics}

In general, telemedicine can be an impactful mechanism for extending the reach of limited healthcare personnel and has been integrated into other clinical settings (Ekeland et al. 2010; Fortney et al. 2013; Terry et al. 2019). Using telemedicine can increase access to specialty services for underserved rural and urban populations. Tele-consultations can circumvent prohibitive travel and associated costs for patients. For patients with genetic disorders, these visits may have to occur on a regular basis for many years, so tele-consultations may maintain the status quo. Furthermore, for referring community providers, telemedicine technology opens up new possibilities for continuing education and training as well as interactions with specialists on a case-by-case basis (Beste et al. 2017). It 
may also be used for educating families and the larger healthcare community.

A systematic review of telemedicine in genetics services reported high levels of patient satisfaction and receptiveness (Hilgart et al. 2012). However, the use of telegenetics as a service delivery model remains low in the US, estimated at $26 \%$ in the most recent report (Beste et al. 2017). The lower uptake may be attributed to limited capacity due to various requirements, such as credentialing and reimbursement for these services. Low adoption rates have been observed in other parts of the world, such as Europe, in addition to the US (Otten et al. 2016a; Otten et al. 2016b). Allocation of financial resources to support telegenetics training, equipment, and technical assistance must be prioritized to increase uptake. Organizational support, leadership buy-in, and a culture oriented towards embracing innovations and change are additional facilitators for telemedicine uptake in genetics. However, the use of telemedicine has dramatically increased with the ongoing novel coronavirus (COVID-19) pandemic. While containing the spread of COVID-19 has been challenging, this situation has allowed clinicians to demonstrate the utility of telemedicine technologies. Particular to the US, the growing number of virtual "office" visits presents an opportunity to expand telemedicine and bring specialty care services, such as genomic medicine, to patients in underserved areas who otherwise would lack such access (Rockwell and Gilroy 2020).

\section{Partnership trio}

Since the introduction of the PCMH, the model has continued to be adapted and refined. As an adaptation of this and similar models, a partnership trio among non-genetics providers, clinical genetics providers, and parents/families would be especially effective. Developing a protocol and providing a mechanism to connect PCPs and genetic providers via genetic counselors or telegenetics would enhance access to genetic services, which is precisely what the partnership trio entails. When piloting their collaborative model, Kubendran and colleagues demonstrated high patient satisfaction and shortened wait time to receive appropriate genetic care (Kubendran et al. 2016). The widespread paucity of pertinent resources has compelled parents and families who have children with special healthcare needs to formalize support groups to share knowledge, provide peer support, facilitate connection to services, and advocate for policy change (Genetic Alliance 2019; Beste et al. 2017). Linking clinical and family partners and

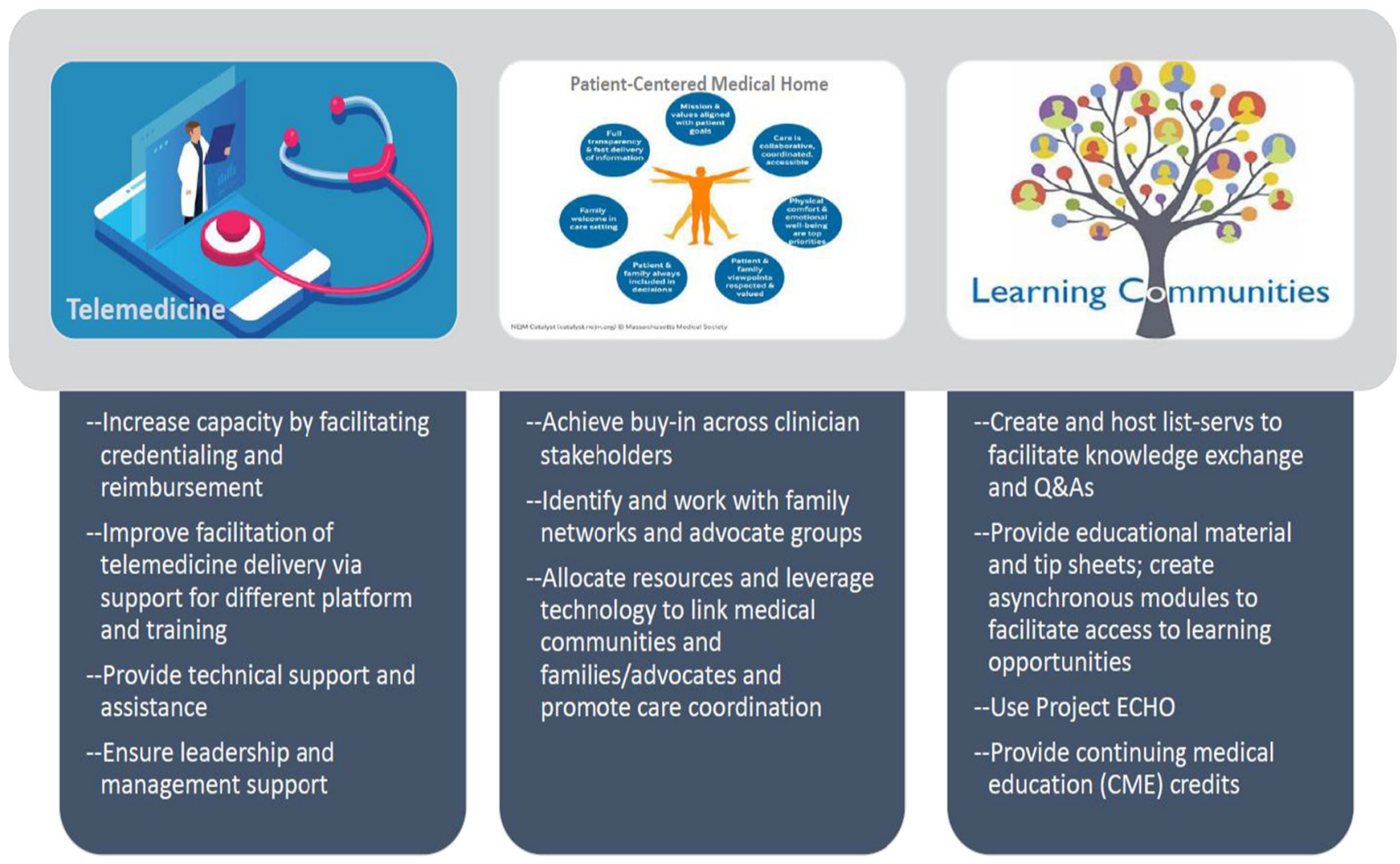

Graphics credits: Johns Hopkins University (telemedicine); New England Journal of Medicine (patient-centered medical home); Greater Tacoma Community Foundation (learning communities)

Fig. 3 Recommendations for strategies to integrate medical genetics and primary care 
their efforts as a trio can significantly improve access to genetic services.

\section{Learning communities}

Enhanced training, evidence-based guidelines, and clinical tools support effective delivery of or facilitate access to genomic medicine by PCPs (Hauser et al. 2018). Access to information and expertise in genetics provides a critical resource for PCPs. Learning communities may represent a mechanism by which to facilitate information exchange and knowledge sharing among genetic and non-genetic providers. Within communities of clinicians, using a listserv to host questions and responses has been an effective way to share information. List-servs may also allow clinicians to have certain questions answered in real time. Moreover, little is known about the education needs of those providing wrap-around and social services, such as home visitors and early interventionists, as well as family support networks, and it would be beneficial to include those in the learning communities. These groups may also offer perspectives that would highly complement the clinical care delivery, thereby enhancing the overall education of all in the community.

Another strategy is using Project ECHO ${ }^{\mathrm{TM}}$ (Extension for Community Healthcare Outcomes), an interactive and evidence-based approach that provides medical education for managing complex and traditionally specialist-managed health conditions through tele-mentoring and comanagement of patients with PCPs (University of New Mexico 2019). It is a model that is particularly well suited to serve patients in underserved areas. ECHO connects specialists located in academic centers (i.e., hubs) and community primary care sites (i.e., spokes) through the use of technology to improve communication and learning (Katzman et al. 2016). The ECHO model has demonstrated success in managing chronic conditions and now operates more than 90 hubs covering more than 45 diseases and health conditions in 16 countries (Arora et al. 2011a; b; Kaye et al. 2019). Arora and colleagues demonstrated that the quality of hepatitis $\mathrm{C}$ care provided by Project ECHO-trained PCPs was equal to that of care provided by university-based specialists (Arora et al. 2011a; b). Following a similar path, the ECHO model may create a dynamic, all-directional learning community between PCPs and specialists in genetics by enhancing PCPs' knowledge, skillset, confidence, and practice in their local communities (Katzman et al. 2016).

This scoping review is comprehensive and rigorous, identifying both gray literature and articles from MEDLINE, including reference lists from articles extracted from the search. However, this review may not have identified all relevant literature. Although it would have been beyond the scope of this review, the search terms did not include certain terms like telephone conversations, coordination of care, consultation, provider-to-provider correspondence, or group appointments that might have yielded more articles describing strategies and limitations related to traditional methods of healthcare provider collaboration and dissemination of expert information from geneticists. This discussion also did not address alternative healthcare delivery and managed care models specific to genetics that may be more common outside of the US to identify other potential integration strategies.

\section{Conclusions}

To realize genetic and genomic service integration in primary care settings, it is imperative that frontline clinicians be equipped with the knowledge and support they need to manage patients with complex genetic diseases. Multiple strategies to ameliorate access to genetic services in a timely and effective manner are identified, some of which require nominal resource investments for implementation given the ready availability of many modern technologies and overlaps in coordinated care strategies (Fig. 3). By applying the partnership trio model for service delivery, using telegenetics, and leveraging the shared knowledge base of learning communities, it may be possible to create new and enhance existing access points for genetic services for children and adults, especially those who reside in medically underserved communities.

As healthcare infrastructure in the areas of informatics and telemedicine continues to expand, it is necessary for providers to communicate effectively with one another and share information that can benefit patient health outcomes. Recommendations derived from this scoping review can be used to achieve this objective. PCPs may capitalize on these strategies and opportunities to improve genetics service delivery for their patients, which is ultimately the goal of all PCPs.

Acknowledgements An earlier version of this work has been presented at the American Public Health Association Annual Conference, 2019, Philadelphia. This work was supported by a grant from the Health Resources and Services Administration (award number: UH7MC30777).

Funding This study was funded by Health Resources and Services Administration (award number: UH7MC30777).

Data availability N/A

\section{Compliance with ethical standards}

Ethics approval and consent to participate This article does not contain any studies with human participants performed by any of the authors.

Conflict of interest The authors declare that they have no conflict of interest.

Code availability N/A 


\section{References}

Agency for Healthcare Research and Quality (2019) Defining the PCMH. https://pcmh.ahrq.gov/page/defining-pcmh. Accessed 18 Dec 2019

Andermann A, Blancquaert I (2010) Genetic screening: a primer for primary care. Can Fam Physician 56:333-339

Arksey H (2005) Scoping studies: towards a methodological framework. Int J Soc Res Methodol 8:19-32. https://doi.org/10.1080/ 1364557032000119616

Arora S, Kalishman S, Dion D, Som D, Thornton K, Bankhurst A, Boyle J, Harkins M, Moseley K, Murata G, Komaramy M, Katzman J, Colleran K, Deming P, Yutzy S (2011a) Partnering urban academic medical centers and rural primary care clinicians to provide complex chronic disease care. Health Aff 30:1176-1184. https://doi.org/10. 1377/hlthaff.2011.0278

Arora S, Thornton K, Murata G, Deming P, Kalishman S, Dion D, Parish B, Burke T, Pak W, Dunkelberg J, Kistin M, Brown J, Jenkusky S, Komaromy M, Qualls C (2011b) Outcomes of treatment for hepatitis $\mathrm{C}$ virus infection by primary care providers. N Engl J Med 364: 2199-2207. https://doi.org/10.1056/NEJMoa1009370

Balachandra SK, Carroll JK, Fogarty CT, Finigan EG (2009) Familycentered maternity care for deaf refugees: the patient-centered medical home in action. Fam Syst Health 27:362-367

Bell RA, McDermott H, Fancher TL, Green MJ, Day FC, Wilkes MS (2015) Impact of a randomized controlled educational trial to improve physician practice behaviors around screening for inherited breast cancer. J Gen Intern Med 30:334-341. https://doi.org/10. 1007/s11606-014-3113-5

Bernard ME, Zabel CA, Rohrer JE (2010) Improving risk assessment in family medicine through the family history. J Prim Care Community Health 1:147-151. https://doi.org/10.1177/2150131910375841

Beste LA, Glorioso TJ, Ho PM, Au DH, Kirsh SR, Todd-Stenberg J, Chang MF, Dominitz JA, Barón AE, Ross D (2017) Telemedicine specialty support promotes hepatitis $\mathrm{C}$ treatment by primary care providers in the Department of Veterans Affairs. Am J Med 130: 432-438 e433. https://doi.org/10.1016/j.amjmed.2016.11.019

Buchanan AH, Datta SK, Skinner CS, Hollowell GP, Beresford HF, Freeland T, Rogers B, Boling J, Marcom PK, Adams MB (2015) Randomized trial of telegenetics vs. in-person cancer genetic counseling: cost, patient satisfaction and attendance. J Genet Couns 24:961-970. https://doi.org/10.1007/s10897-015-9836-6

Carroll JC et al (2009) Genetic education for primary care providers: improving attitudes, knowledge, and confidence. Can Fam Physician 55:e92-e99

Carroll JC, Allanson J, Morrison S, Miller FA, Wilson BJ, Permaul JA, Telner D (2019) Informing integration of genomic medicine into primary care: an assessment of current practice, attitudes, and desired resources. Front Genet 10:1189. https://doi.org/10.3389/fgene. 2019.01189

Cartmell KB, Sterba KR, Pickett K, Zapka J, Alberg AJ, Sood AJ, Esnaola NF (2018) Availability of patient-centered cancer support services: a statewide survey of cancer centers. PLoS One 13: e0194649. https://doi.org/10.1371/journal.pone.0194649

Chou AF, Norris AI, Williamson L, Garcia K, Baysinger J, Mulvihill JJ (2009) Quality assurance in medical and public health genetics services: a systematic review. Am J Med Genet C: Semin Med Genet 151C:214-234. https://doi.org/10.1002/ajmg.c.30219

Christianson CA, Powell KP, Hahn SE, Blanton SH, Bogacik J, Henrich VC, Genomedical C (2012) The use of a family history risk assessment tool within a community health care system: views of primary care providers. J Genet Couns 21:652-661. https://doi.org/10.1007/ s10897-011-9479-1

Cichon M, Feldman GL (2014) Opportunities to improve recruitment into medical genetics residency programs: survey results of program directors and medical genetics residents. Genet Med 16:413-418. https://doi.org/10.1038/gim.2013.161

Cooksey JA, Forte G, Benkendorf J, Blitzer MG (2005) The state of the medical geneticist workforce: findings of the 2003 survey of American Board of Medical Genetics certified geneticists. Genet Med 7:439-443. https://doi.org/10.1097/01.GIM.0000172416. 35285.9F

Cooksey JA, Forte G, Flanagan PA, Benkendorf J, Blitzer MG (2006) The medical genetics workforce: an analysis of clinical geneticist subgroups. Genet Med 8:603-614

Cornel MC, van El CG (2017) Barriers and facilitating factors for implementation of genetic services: a public health perspective. Front Public Health 5:195. https://doi.org/10.3389/fpubh.2017.00195

Cragun D, Pal T (2013) Identification, evaluation, and treatment of patients with hereditary cancer risk within the United States. ISRN Onc 2013:260847. https://doi.org/10.1155/2013/260847

Daudt HM, van Mossel C, Scott SJ (2013) Enhancing the scoping study methodology: a large, inter-professional team's experience with Arksey and O'Malley's framework. BMC Med Res Methodol 13: 48. https://doi.org/10.1186/1471-2288-13-48

David SP, Johnson SG, Berger AC, Feero WG, Terry SF, Green LA, Phillips RL, Ginsburg GS (2015) Making personalized health care even more personalized: insights from activities of the IOM genomics roundtable. Ann Fam Med 13:373-380. https://doi.org/10. 1370/afm.1772

de Hoog CL, Portegijs PJ, Stoffers HE (2014) Family history tools for primary care are not ready yet to be implemented: a systematic review. Eur J Gen Pract 20:125-133. https://doi.org/10.3109/ 13814788.2013.840825

Ekeland AG, Bowes A, Flottorp S (2010) Effectiveness of telemedicine: a systematic review of reviews. Int J Med Inform 79:736-771. https:// doi.org/10.1016/j.ijmedinf.2010.08.006

Fortney JC, Pyne JM, Mouden SB, Mittal D, Hudson TJ, Schroeder GW, Williams DK, Bynum CA, Mattox R, Rost KM (2013) Practicebased versus telemedicine-based collaborative care for depression in rural federally qualified health centers: a pragmatic randomized comparative effectiveness trial. Am J Psychiatry 170:414-425. https://doi.org/10.1176/appi.ajp.2012.12050696

Genetic Alliance (2019) Advocacy, education \& empowerment. http:// geneticalliance.org/. Accessed 18 Dec 2019

Hamilton AB, Oishi S, Yano EM, Gammage CE, Marshall NJ, Scheuner MT (2014) Factors influencing organizational adoption and implementation of clinical genetic services. Genet Med 16:238-245. https://doi.org/10.1038/gim.2013.101

Harding B, Webber C, Ruhland L, Dalgarno N, Armour CM, Birtwhistle R, Brown G, Carroll JC, Flavin M, Phillips S, MacKenzie JJ (2019) Primary care providers' lived experiences of genetics in practice. J Commun Genet 10:85-93. https://doi.org/10.1007/s12687-0180364-6

Harvey EK, Fogel CE, Peyrot M, Christensen KD, Terry SF, McInerney JD (2007) Providers' knowledge of genetics: a survey of 5915 individuals and families with genetic conditions. Genet Med 9:259-267. https://doi.org/10.1097/GIM.0b013e31805002f2

Hauser D, Obeng AO, Fei K, Ramos MA, Horowitz CR (2018) Views of primary care providers on testing patients for genetic risks for common chronic diseases. Health Aff 37:793-800. https://doi.org/10. 1377/hlthaff.2017.1548

Henson BL, Williamson Dean L, Chen J, Danylchuk NR (2016) What are employers looking for when hiring genetic counselors? An analysis of advertised positions. Unpublished work

Hilgart JS, Hayward JA, Coles B, Iredale R (2012) Telegenetics: a systematic review of telemedicine in genetics services. Genet Med 14: $765-776$

Kaplan CP (2014) A randomized, controlled trial to increase discussion of breast cancer in primary care. Cancer Epidemiol Biomark Prev 23: 1245-1253. https://doi.org/10.1158/1055-9965.EPI-13-1380 
Katzman JG, Galloway K, Olivas C, McCoy-Stafford K, Duhigg D, Comerci G, Kalishman S, Buckenmaier CC, McGhee L, Joltes K, Bradford A, Shelley B, Hernandez J, Arora S (2016) Expanding health care access through education: dissemination and implementation of the ECHO model. Mil Med 181:227-235

Kaye C (2012) Genetic service delivery: infrastructure, assessment and information. Public Health Genomics 15:164-171. https://doi.org/ $10.1159 / 000335552$

Kaye C et al (2019) Regional models of genetic services in the United States. Genet Med 22:381-388. https://doi.org/10.1038/s41436019-0648-1

Kne A, Zierhut H, Baldinger S, Swenson KK, Mink P, Veach PM, Tsai ML (2017) Why is cancer genetic counseling underutilized by women identified as at risk for hereditary breast cancer? Patient perceptions of barriers following a referral letter. J Genet Couns 26:697715. https://doi.org/10.1007/s10897-016-0040-0

Kubendran S, Sivamurthy S, Schaefer GB (2016) A novel approach in pediatric telegenetic services: geneticist, pediatrician and genetic counselor team. Genet Med 19(11):1260-1267

Lopes-Junior LC, Carvalho Junior PM, de Faria Ferraz VE, Nascimento LC, Van Riper M, Floria-Santos M (2017) Genetic education, knowledge and experiences between nurses and physicians in primary care in Brazil: a cross-sectional study. Nurs Health Sci 19:6674. https://doi.org/10.1111/nhs.12304

Maiese DR, Keehn A, Lyon M, Flannery D, Watson M, Working Groups of the National Coordinating Center for Seven Regional Genetics Service C (2019) Current conditions in medical genetics practice. Genet Med 21:1874-1877. https://doi.org/10.1038/s41436-0180417-6

Mays N, Roberts E, Popay J (2001) Synthesizing research evidence. In: Fulop, Allen, Clarke, Black, eds. Studying the organisation and delivery of health services: research methods. Routledge: London

McCahon D, Holder R, Metcalfe A, Clifford S, Gill P, Cole T, Sleightholme HV, Wilson S (2009) General practitioners' attitudes to assessment of genetic risk of common disorders in routine primary care. Clin Genet 76:544-551. https://doi.org/10.1111/j.13990004.2009.01245.x

McDonald E, Lamb A, Grillo B, Lucas L, Miesfeldt S (2014) Acceptability of telemedicine and other cancer genetic counseling models of service delivery in geographically remote settings. J Genet Couns 23:221-228. https://doi.org/10.1007/s10897-0139652-9

Mead H, Andres E, Regenstein M (2014) Underserved patients' perspectives on patient-centered primary care: does the patient-centered medical home model meet their needs? Med Care Res Rev 71:6184. https://doi.org/10.1177/1077558713509890

Mikat-Stevens NA, Larson IA, Tarini BA (2015) Primary-care providers' perceived barriers to integration of genetics services: a systematic review of the literature. Genet Med 17:169-176. https://doi.org/10. 1038/gim.2014.101

Najafzadeh M, Davis JC, Joshi P, Marra C (2013) Barriers for integrating personalized medicine into clinical practice: a qualitative analysis. Am J Med Genet A 161A:758-763. https://doi.org/10.1002/ajmg.a. 35811

Orlando LA, Wu RR, Beadles C, Himmel T, Buchanan AH, Powell KP, Hauser ER, Henrich VC, Ginsburg GS (2014) Implementing family health history risk stratification in primary care: impact of guideline criteria on populations and resource demand. Am J Med Genet C: Semin Med Genet 166C:24-33. https://doi.org/10.1002/ajmg.c. 31388

Otten E, Birnie E, Lucassen AM, Ranchor AV, Van Langen IM (2016a) Telemedicine uptake among genetics professionals in Europe: room for expansion. Eur J Hum Genet 24:157-163. https://doi.org/10. 1038/ejhg.2015.83

Otten E, Birnie E, Ranchor AV, van Langen IM (2016b) Telegenetics use in presymptomatic genetic counselling: patient evaluations on satisfaction and quality of care. Eur J Hum Genet 24:513-520. https://doi.org/10.1038/ejhg.2015.164

Paneque M, Turchetti D, Jackson L, Lunt P, Houwink E, Skirton H (2016) A systematic review of interventions to provide genetics education for primary care. BMC Fam Pract 17:89. https://doi.org/ 10.1186/s12875-016-0483-2

Pham MT, Rajic A, Greig JD, Sargeant JM, Papadopoulos A, McEwen SA (2014) A scoping review of scoping reviews: advancing the approach and enhancing the consistency. Res Synth Methods 5: 371-385. https://doi.org/10.1002/jrsm.1123

Rahimzadeh V, Bartlett G (2014) Genetics and primary care: where are we headed? J Transl Med 12:238. https://doi.org/10.1186/s12967014-0238-6

Rockwell KL, Gilroy AS (2020) Incorporating telemedicine as part of COVID-19 outbreak response systems. Am J Manag Care 26:147148. https://doi.org/10.37765/ajmc.2020.42784

Rolnick SJ, Rahm AK, Jackson JM, Nekhlyudov L, Goddard KAB, Field T, McCarty C, Nakasato C, Roblin D, Anderson CP, Valdez R (2011) Barriers in identification and referral to genetic counseling for familial cancer risk: the perspective of genetic service providers. J Genet Couns 20:314-322. https://doi.org/10.1007/s10897-0119351-3

Sane V, Humphreys L, Peterson M (2015) Are Australasian genetic counselors interested in private practice at the primary care level of health service? J Genet Couns 24:783-796

Saul RA (2013) Genetic and genomic literacy in pediatric primary care. Pediatr 132:S198-S202. https://doi.org/10.1542/peds.2013-1032C

Scott J, Trotter T (2013) Primary care and genetics and genomics. Pediatr 132:S231-S237

Senier L, Kearney M, Orne J (2015) Using public-private partnerships to mitigate disparities in access to genetic services: lessons from Wisconsin. Adv Med Sociol 16:269-305. https://doi.org/10.1108/ S1057-629020150000016010

Stein Q (2016) GC student training slots vs. NSGC job postings 2011 to 2015

Stevens GD, Kim AY (2016) National trends in indicators of a medical home for children. Matern Child Health J 20:730-739. https://doi. org/10.1007/s10995-015-1902-Z

Tarini BA, Zikmund-Fisher BJ, Saal HM, Edmondson L, Uhlmann WR (2015) Primary care providers' initial evaluation of children with global developmental delay: a clinical vignette study. J Pediatr 167:1404-1408.e1401. https://doi.org/10.1016/j.jpeds.2015.08.065

Terry AB, Wylie A, Raspa M, Vogel B, Sanghavi K, Djurdjinovic L, Caggana M, Bodurtha J (2019) Clinical models of telehealth in genetics: a regional telegenetics landscape. J Genet Couns 28:673691. https://doi.org/10.1002/jgc4.1088

Traxler LB (2014) Implementing a screening tool for identifying patients at risk for hereditary breast and ovarian cancer: a statewide initiative. Ann Surg Oncol 21:3342-3347. https://doi.org/10.1245/s10434014-3921-1

Ufer LG, Moore JA, Hawkins K, Gembel G, Entwistle DN, Hoffman D (2018) Care coordination: empowering families, a promising practice to facilitate medical home use among children and youth with special health care needs. Matern Child Health J 22:648-659. https://doi.org/10.1007/s10995-018-2477-2

Unim B, Pitini E, Lagerberg T, Adamo G, De Vito C, Marzuillo C, Villari P (2019) Current genetic service delivery models for the provision of genetic testing in Europe: a systematic review of the literature. Front Genet 10:552. https://doi.org/10.3389/fgene.2019.00552

University of New Mexico Project ECHO: A Revolution in Medical Education and Care Delivery. https://echo.unm.edu. Accessed Jun 302019

Wakefield CE, Quinn VF, Fardell JE, Signorelli C, Tucker KM, Patenaude AF, Malkin D, Walwyn T, Alvaro F, Cohn RJ (2018) Family history-taking practices and genetic confidence in primary 
and tertiary care providers for childhood cancer survivors. Pediatr Blood Cancer 65. https://doi.org/10.1002/pbc.26923

Wilkes MS, Day FC, Fancher TL, McDermott H, Lehman E, Bell RA, Green MJ (2017) Increasing confidence and changing behaviors in primary care providers engaged in genetic counselling. BMC Med Educ 17:163. https://doi.org/10.1186/s12909-017-0982-4

Williams JL, Rahm AK, Zallen DT, Stuckey H, Fultz K, Fan AL, Bonhag M, Feldman L, Segal MM, Williams MS (2018) Impact of a patient- facing enhanced genomic results report to improve understanding, engagement, and communication. J Genet Couns 27:358-369. https://doi.org/10.1007/s10897-017-0176-6

Publisher's note Springer Nature remains neutral with regard to jurisdictional claims in published maps and institutional affiliations. 